\title{
Mobilization of Phosphorus, Potassium and Silicon in the Greenhouse Ground at Application of Bacterial Preparations
}

\author{
E. P. Kiryushin, E. B. Pashkevich, E. L. Neymatov, O. M. Seliverstova and N. V. Verkhovtseva \\ Department of Agrochemistry and Plant's Biochemistry, Lomonosov Moscow State University, Moscow, Leninskii Gory 119991, \\ Russia
}

Received: March 24, 2011 / Published: November 20, 2011

\begin{abstract}
The investigation of $\mathrm{P}, \mathrm{K}$ and $\mathrm{Si}$ mobilization dynamics in greenhouse ground with the application of selective microorganisms and diatomite was the purpose of this work. The substrate for laboratory research was ground (peat and perlite mixture-PP), diatomite (D) and bacterial preparations, which were introduced into the ground. Four bacteria isolated of environment places: from soils_-Bacillus macerans and Bacillus circulans and from surface of sand-Bacillus circulans 2 and Corynebacterium sp. have been applied as a basis of bacterial preparations. Experiment included 10 variants: two grounds (PP and PPD) and 8 variants with treating ground of each of four bacterial preparations. The results showed that the content of water-soluble elements forms in a ground with microorganisms after 56 days has increased: $\mathrm{P}$ and $\mathrm{K}$-in 10 times, Si-in 3 times. It proved efficiency of bacterial cultures in the mobilization of these elements. The most active microorganisms were those that have been isolated from surface of sand (Corynebacterium sp. and Bacillus circulans 2). The mixture of ground and diatomite showed the best efficiency. The best ground microbes' community was investigated using chemo diagnostic method gas chromatography-mass spectrometry. It has been shown that the content of Acetobacterium sp. (the culture capable to formation of acetic acid in an anaerobic metabolism), had increased to the end of composting period in 10 times and the number of Bacillus sp.- as minimum in 100 times.
\end{abstract}

Key words: Bacterial preparation, greenhouse ground, mobilization of $\mathrm{P}, \mathrm{K}, \mathrm{Si}$, nutrients.

\section{Introduction}

One of the major factors which influences growth and development of plants is content of mobile forms of phosphorus and potassium. The considerable quantity of phosphorus, potassium and silicon is in an immobilization condition in greenhouse ground, as a rule [1]. Mobilization of phosphates, potassium and silicon are possible at use of siliceous fertilizers [2] and microbiological preparations [3]. Processing by biological products concerns non-polluting ways of transfer of these elements in soluble form.

It is known [3], that the mineral skeleton from

Corresponding author: E. B. Pashkevich, Ph.D., research fields: agrochemistry, microbiology, roses, greenhouse ground and bacterial preparation. E-mail: pashkevich05@list.ru. silicon bond collapses under the influence of silicate bacteria for the account slimes and enzyme silicase. However, in the pure state these enzymes are not allocated. If these bacteria are cultivated in the siliceous environment in absence of phosphorus the phosphorus entering into their structure, is gradually replaced with silicon. Silicon arrives in cages of these bacteria in a kind anion silicate or in the form of connection with phospho glycerin aldehyde and partially bonds through atom of nitrogen with fibers, amino acids and amino sucroses, and also with carbohydrates by means of formation of bonds $\mathrm{Si}-\mathrm{O}-\mathrm{C}$ [4]. These effects may have been caused the action of rhizosphere microbes which are capable to change acidity of environment locally $[5,6]$. 
Besides, under the literary data low-molecular forms of silicon promote mobilization of phosphorus and potassium soils [7]. Silicon can reduce activity hydroxide aluminum and iron, magnesium, manganese [8]. It is capable to connect soil parts silicon bridges [9]. Thanks to it the moisture capacity and buffer action of easy soils improve aggregation [10]. Silicon connections possess high sorption ability. Hence, at their application reduced the leaching of nutrients [11].

The objective of the work was to study ways of mobilizations potassium and phosphorus and silicon in a ground with use of selective microorganisms and silicon contains fertilizers (diatomite).

\section{Materials and Methods}

The laboratory experiment' objects were some kinds of grounds: mix of peat and perlite-PP ratio 3:1, mix of peat + perlite + diatomite - PPD ratio 500 (PP) : 1 (D) and four bacteria isolated of environment places. There are species from soils-Bacillus macerans and Bacillus circulans and from surface of sand-Bacillus circulans 2 and Corynebacterium sp. Experiment included 10 variants: two grounds and 8 variants with treating ground of each of four bacterial preparations. All mixes were placed in open plastic vessels volume of $0.25 \mathrm{~L}$ and were incubated at room temperature during 56 days. The water content was set to $70 \%-75 \%$. All variants were carried out in three replications.

The experimental design was the following:

1. PP: peat + perlite

2. PP1: peat + perlite + Bacillus macerans

3. PP2: peat + perlite + Bacillus circulans

4. PP3: peat + perlite + Corynebacterium sp.

5. PP4: peat + perlite + Bacillus circulans 2

6. PPD: peat + perlite + diatomite

7. PPD1: peat + perlite + diatomite + Bacillus macerans

8. PPD2: peat + perlite + diatomite + Bacillus circulans

9. PPD3 - peat + perlite + diatomite +
Corynebacterium sp.

10. PPD4 - peat + perlite + diatomite + Bacillus circulans 2

Diatomite is natural Si-rich material $\left(82 \% \mathrm{Si}_{\text {total }}\right.$, $42 \% \mathrm{Si}_{\text {amorphous }}$ ), which has agricultural benefits [12].

The phosphorus and silicon maintenance analyses were carried out in an aqueous extract of ground with Denizhe colorimetric measurements, potassium —on a flame photometer.

The method of microbial diagnostic based on gas chromatography-mass spectrometry of fatty acids, hydroxy acids and fatty aldehydes was applied for study of microbial community's ground. At present time structure of fatty acids of the majority of microorganisms and structure reproducibility is studied, shown specificity of fatty acids of bacterial species and genera. The algorithm of detecting of mass spectral parameters of the sample allows defining about two hundred fatty acids, aldehydes and sterols to define more than 170 species or genera of microorganisms. The advantage of analytical procedure consists in direct extraction these compounds (markers) from sample by chemical procedure and calculates (reconstruct) the composition of the microbial community, encoded in the markers of the sample.

GC-MS analysis was provided by chromate-mass-spectrometer AT-5973 D (Agillent Technologies, USA). A special program was designed for selective detection with accumulation of specific ion signals from microorganism marker compounds. The areas of marker's peaks were integrated automatically (mass-fragmentography) and supervised manually under regular programs of the device with using of internal standard. Then these data were input into account program prepared in electronic EXCEL tables. The method allows defining species of bacteria number more than $10^{3}-10^{4}$ cells $/ g$ of ground.

The methodology of a molecular method of a gas chromatography-mass spectrometry (GC-MS) was in detail presented by Refs. [13, 14]. 
Number of microorganisms with degradation activity to Si-substances was defined by Kokh's method on nutrient medium for such bacteria with nepheline as a source of potassium and silicon.

The method of a gas chromatography (GC) was applied for study of volatile fatty acids of anaerobic microorganism's grounds. GC analysis was provided by gas chromatograph GC-14 A (Shimadzu, Japan).

\section{Results}

The $\mathrm{pH}$ value changed from 6.0 to $5.5-5.2$ for 56 days. The water content was set to $70 \%-75 \%$.

Water-soluble forms of $\mathrm{P}, \mathrm{K}$ and $\mathrm{Si}$ content essentially increased after processing with all microbes preparations: $\mathrm{P}$ and $\mathrm{K}$ increased in 10 times
(Figs. 1-3), $\mathrm{Si}-3$ times.

The maintenance of potassium has essentially increased within one week after processing by microbes preparations by all variants, except for PP variant (Fig. 1).

The phosphorus content (Fig. 2) has considerably grown within one week and finally its quantity has made $90-100 \mathrm{mg} / 100 \mathrm{~g}$ a ground on variants with all biological preparations treatment, except for PP3.

The tendency to increase in the maintenance of water-soluble silicon was observed by all variants of experience in comparison with background variants (Fig. 3). Most significantly it is expressed on variants about application of strains 3 and 4 . The silicon content has made $40-50 \mathrm{mg} / \mathrm{kg}$ of a ground. The bacterial

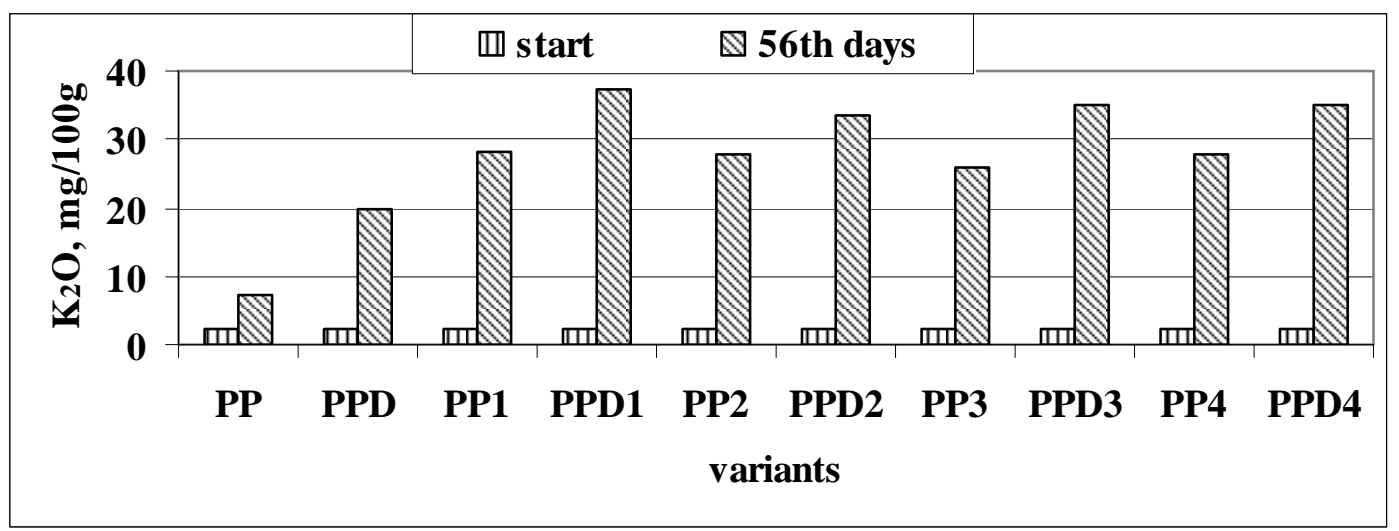

Fig. 1 Change of potassium content in grounds.

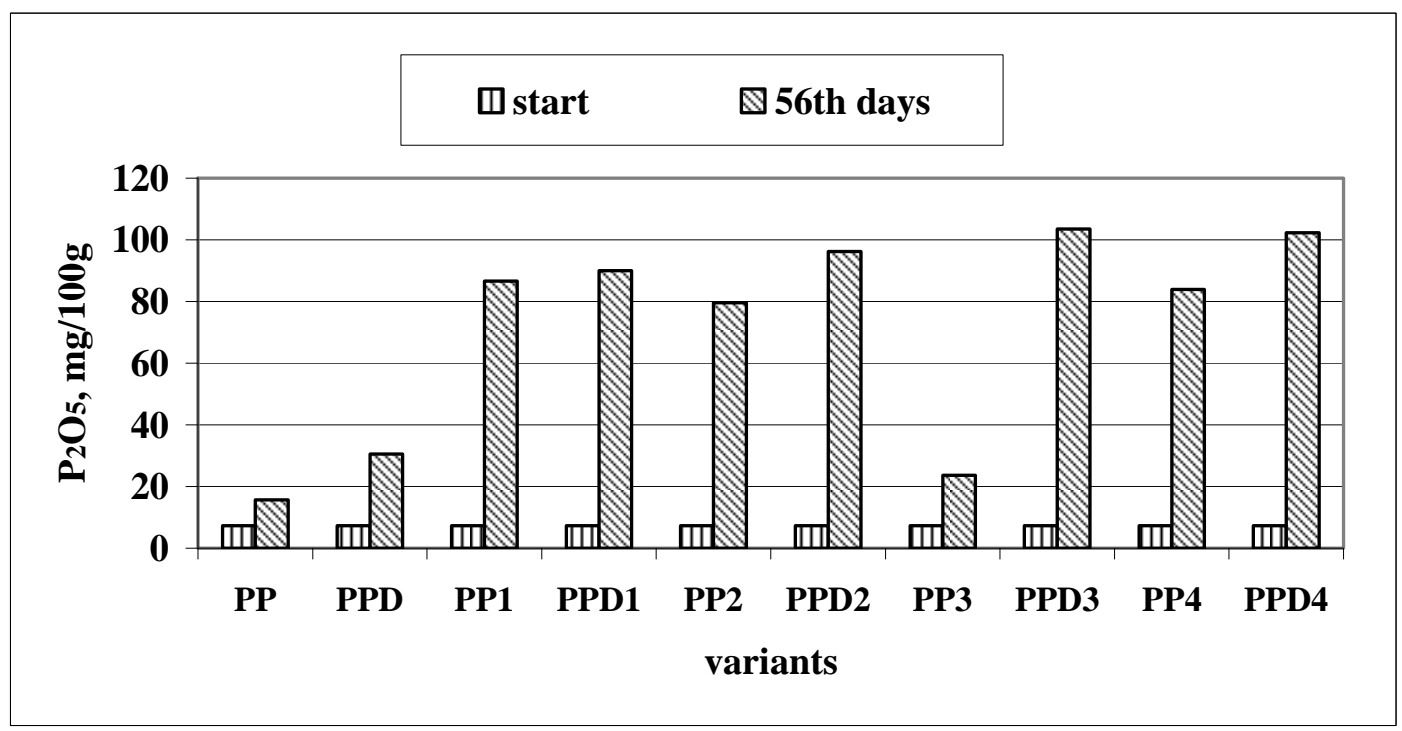

Fig. 2 Change of phosphorus content in grounds. 


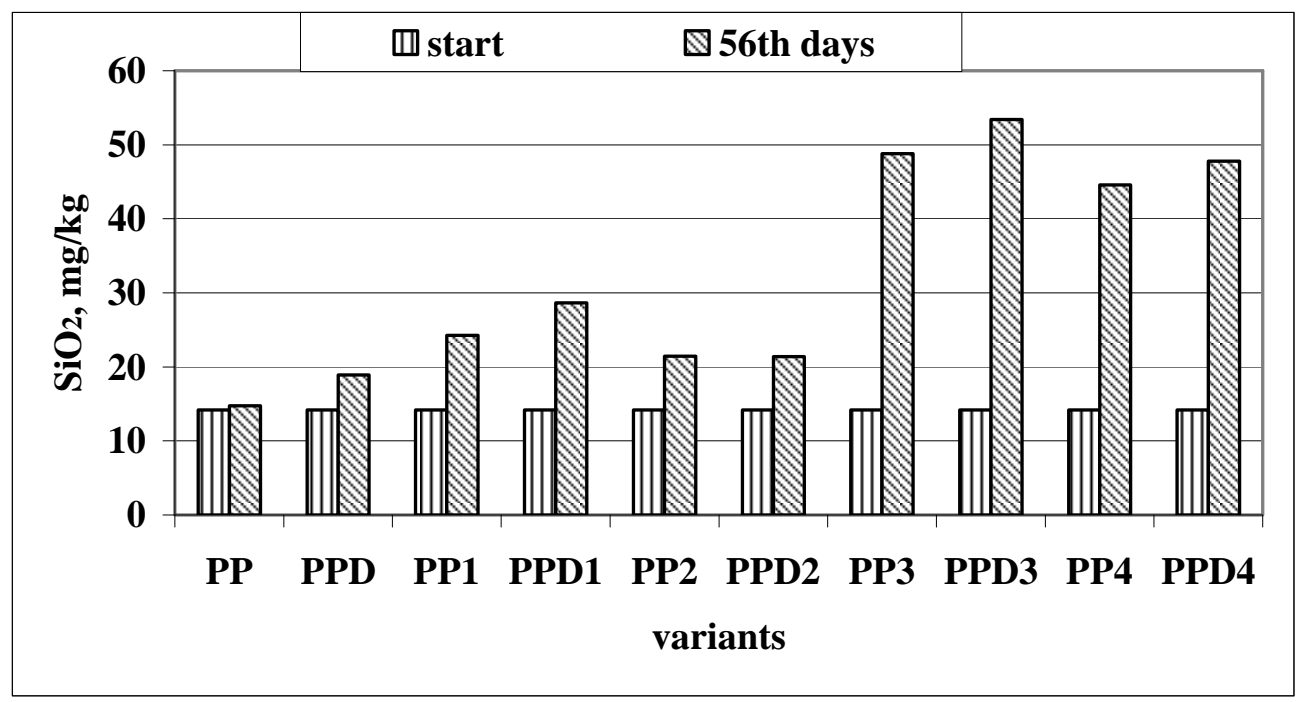

Fig. 3 Change of silicon content in grounds.

cultures treatment of grounds, promote transfer of silicon from insoluble to water-soluble forms, but their activity differed. The best efficiency in mobilizing showed the mixture of ground + diatomite + Bacillus circulans 2 (variant PPD3).

The soil microbes' community was investigated using chemodiagnostic method for study of microbial community's reorganization of ground with diatomite's additives. The data about structure of microbial community of tree variants of ground are presented (Table 1). Microbial population densities were usually high $\left(10^{6}-10^{8}\right.$ cells per of ground).

Altogether, 33 genera of microorganisms were revealed in PP (with 43 species) and 36 genera (44 species) in PPD communities in comparison with 34 genera from PPD + BP (42 species). Thus, the species diversity appears to be higher in the presence of diatomite with addition of PP substrate in comparison with PP microbial' composition. Microorganism's number in this variant of compost on $30 \%$ lower even in the end of experiment.

The structure of the microbial community of the ground with addition of Bacillus circulans 2 had changed during the composting, as quantitatively (microorganism's number decreased approximately on $30 \%$ ), and in a qualitatively.

Table 1 Structure of microbes' community of ground peat-perlite (PP) at addition diatomite (PPD) and bacterial preparations (PPD + BP).

\begin{tabular}{lcccccc}
\hline Microorganisms $\left(\right.$ cells $\left./ \mathrm{g} \times 10^{6}\right)$ & PP & PP & PPD & PPD & PPD + BP & PPD + BP \\
\cline { 2 - 7 } & Initial & 56 days & Initial & 56 days & Initial & 56 days \\
\hline Acetobacter sp. & 59.7 & 75.1 & 25.1 & 29.4 & 56.5 & 28.8 \\
Agrobacterium radiobacter & 0.0 & 0.0 & 1.6 & 2.4 & 0.0 & 0.0 \\
Methylococcus sp. & 8.2 & 7.3 & 0.3 & 1.6 & 9.5 & 3.7 \\
Ochrobactrum sp. & 6.4 & 5.9 & 0.8 & 1.1 & 4.8 & 2.8 \\
Pseudomonas fluorescens & 2.9 & 3.5 & 1.0 & 1.2 & 2.8 & 2.5 \\
P. putida & 9.7 & 9.4 & 3.2 & 2.8 & 9.6 & 6.4 \\
P. vesicularis & 8.1 & 8.3 & 3.5 & 3.1 & 9.0 & 4.8 \\
Riemirella sp. & 0.0 & 0.0 & 1.8 & 2.2 & 0.0 & 0.0 \\
Sphingobacterium spiritovorum & 2.5 & 2.9 & 0.6 & 0.2 & 2.5 & 2.0 \\
Sphingomonas adgesiva & 2.0 & 2.3 & 0.6 & 0.8 & 2.1 & 1.6 \\
Sphingomonas capsulata & 3.9 & 4.5 & 1.1 & 1.7 & 3.8 & 3.0 \\
Xanthomonas sp. & 7.6 & 7.2 & 2.1 & 2.8 & 6.9 & 4.2 \\
\hline
\end{tabular}


(Table 1 continued).

\begin{tabular}{|c|c|c|c|c|c|c|}
\hline \multirow{2}{*}{ Microorganisms (cells/g $\times 10^{6}$ ) } & $\mathrm{PP}$ & $\mathrm{PP}$ & PPD & PPD & $\mathrm{PPD}+\mathrm{BP}$ & $\mathrm{PPD}+\mathrm{BP}$ \\
\hline & Initial & 56 days & Initial & 56 days & Initial & 56 days \\
\hline FeRed & 0.4 & 0.3 & 2.5 & 1.6 & 0.3 & 0.8 \\
\hline Aeromonas hydrophila & 42.4 & 35.7 & 10.9 & 11.4 & 36.5 & 23.6 \\
\hline Bacteroides fragilis & 0.5 & 3.1 & 0.8 & 1.1 & 1.0 & 0.0 \\
\hline Bacteroides fragilis & 0.5 & 3.1 & 0.8 & 1.1 & 1.0 & 0.0 \\
\hline Bacteroides ruminicola & 3.6 & 3.6 & 1.2 & 1.0 & 3.1 & 2.0 \\
\hline$W A R B^{*}$ & 9.8 & 7.3 & 3.2 & 4.0 & 7.6 & 5.3 \\
\hline Desulfovibrio sp. & 1.6 & 3.3 & 0.0 & 0.0 & 2.7 & 1.5 \\
\hline Chlamydia sp. & 0.4 & 0.3 & 0.0 & 0.2 & 0.3 & 0.0 \\
\hline Nitrobacter sp. & 0.0 & 0.0 & 4.3 & 5.1 & 0.0 & 0.0 \\
\hline Cytophaga sp. & 7.3 & 6.2 & 2.1 & 2.5 & 5.8 & 3.6 \\
\hline Arthrobacter sp. & 3.1 & 4.1 & 3.8 & 5.1 & 3.6 & 2.2 \\
\hline Enterococcus sp. & 4.7 & 6.4 & 4.7 & 2.5 & 6.6 & 0.0 \\
\hline Caulobacter sp. & 2.4 & 2.0 & 1.1 & 1.4 & 1.4 & 10.5 \\
\hline Bacillus subtilis & 1.2 & 1.1 & 4.0 & 5.0 & 1.0 & 1.2 \\
\hline Bacillus sp. & 0.0 & 0.0 & 2.1 & 2.5 & 0.0 & 1.0 \\
\hline Clostridium difficile & 0.0 & 0.5 & 0.0 & 0.0 & 0.1 & 0.2 \\
\hline C. pasteurianum & 7.3 & 8.2 & 0.3 & 1.6 & 9.5 & 3.7 \\
\hline C. perfringens & 0.5 & 0.4 & 0.2 & 0.3 & 0.3 & 0.3 \\
\hline C. propionicum & 0.0 & 0.0 & 0.0 & 0.0 & 2.4 & 0.7 \\
\hline Acetobacterium sp. & 0.0 & 0.0 & 0.5 & 0.3 & 0.5 & 4.7 \\
\hline Butyrivibrio 1-4-11 & 0.1 & 0.5 & 0.6 & 0.4 & 0.1 & 0.5 \\
\hline Butyrivibrio 1-2-13 & 3.9 & 4.2 & 0.0 & 0.0 & 4.8 & 0.0 \\
\hline Butyrivibrio 7S-14-3 & 11.5 & 16.3 & 11.8 & 16.1 & 14.0 & 9.5 \\
\hline Bifidobacterium sp. & 0.4 & 0.4 & 0.6 & 0.8 & 0.4 & 1.0 \\
\hline Corynebacterium sp. & 1.0 & 1.2 & 1.4 & 1.9 & 1.1 & 0.8 \\
\hline Eubacterium lentum & 1.6 & 2.0 & 0.0 & 0.0 & 2.1 & 1.1 \\
\hline Eubacterium sp. & 0.2 & 0.2 & 2.3 & 2.6 & 0.1 & 0.4 \\
\hline Propionibacterium freudenreichii & 7.6 & 7.5 & 5.8 & 0.0 & 7.3 & 7.6 \\
\hline P. jensenii & 10.9 & 11.0 & 5.2 & 5.8 & 9.4 & 8.9 \\
\hline Propionibacterium sp. & 0.0 & 0.0 & 0.8 & 1.4 & 0.0 & 0.0 \\
\hline Mycobacterium sp. & 3.0 & 6.0 & 8.8 & 9.9 & 4.4 & 4.8 \\
\hline Rhodococcus equi & 1.1 & 1.2 & 0.6 & 0.8 & 1.6 & 2.8 \\
\hline Rhodococcus terrae & 6.2 & 8.4 & 10.0 & 10.8 & 5.5 & 4.2 \\
\hline Pseudonocardia sp. & 0.2 & 0.4 & 1.2 & 1.6 & 0.8 & 0.7 \\
\hline Streptomyces-Nocardiopsis & 5.9 & 7.5 & 6.4 & 7.6 & 6.4 & 3.8 \\
\hline Nocardia carnea & 1.0 & 1.1 & 1.0 & 1.3 & 1.2 & 0.7 \\
\hline Actinomadura roseola & 0.5 & 0.8 & 0.8 & 0.9 & 0.5 & 0.4 \\
\hline Total & 266 & 265 & 140 & 156 & 251 & 168 \\
\hline
\end{tabular}

* Wolinella - Acholeplasma - Roseomonas - Burkholderia;

PP: ground of peat-perlite (1:3), PPD: ground of peat-perlite-diatomite; BP: bacterial preparation on the basis of suspension Bacillus circulans 2 in concentration $10^{6}$ cells $/ \mathrm{mL}$;

The number of Bacillus sp. increased as minimum in 100 times (Table 1).

The number of some species has increased. There was Acetobacterium sp. that has increased to the end of composting period in 10 times.

The data of volatile fatty acids studied by a method of a gas chromatography is presented (Table 2).

\section{Discussion}

On variants with microbial processing growth of 
Table 2 Metabolites (volatile fatty acids) of an anaerobic microorganism's grounds.

\begin{tabular}{ll}
\hline Metabolites & $\mathrm{Mkl} / \mathrm{mL}$ \\
\hline Acetic & $30.20 \pm 2.90$ \\
Propionic & $1.05 \pm 0.15$ \\
Isobutyric & $0.65 \pm 0.05$ \\
Butyric & $0.35 \pm 0.15$ \\
Isovarianic & 0.60 \\
Varianic & 0.07 \\
Isocapronic & 0.05 \\
Capronic & 0.07 \\
\hline
\end{tabular}

quantity water-soluble potassium in a ground is caused by activity of microorganisms, the greatest increase in quantity has occurred on a variant to application of Corynebacterium sp. On variants with diatomite higher indications on potassium are regularly shown (Fig. 1). Apparently, it is caused by leaching potassium from diatomite. A quantity of this element is in the water-soluble form in diatomite [12].

We supposed that a significant role in increase of nutrients' concentration in ground belongs to microorganisms both autochthonic and allochthonic.

The best efficiency in mobilizing showed the mixture of ground + diatomite + Bacillus circulans 2 . This strain was isolated from the sand surface and process of silicon and potassium' leaching for this culture is natural property unlike phosphorus.

Higher biodiversity is in a variant with diatomite (PPD) in comparison with PPD + BP (Table 1) might be connected with substrate inhibition due to excess of PP organic matter and effect of dilution with diatomite additives. Really, the maintenance of organic matter in diatomite is not enough and its additive only dilutes a substratum. Microorganism's number in this variant of compost on $30 \%$ lower even in the end of experiment in comparison with the PP.

The number of Bacillus sp. increased as minimum in 100 times in variant PPD, in comparison with PP. Such increase in bacilli number occurred, apparently, at the expense of species with degradation activity to Si-substances, which have been brought by us in a ground with biological preparations (allochthonic microorganism). By Kokh's method on nutrient medium for such bacteria the increase in their number in 100 times in the end of experiment has been shown as well.

Decrease in number of microorganisms in variant with addition of Bacillus circulans 2 has occurred at the expense of a number of aerobic (Pseudomonas putida, P. vesicularis, Methylococcus sp.) and anaerobic (Bacteroides hypermegas, B. ruminicola) microorganisms. Considering, that Bacteroides capable to form butyric acid in considerable quantities, and Enterococcus sp. can destroy humus acid, decrease in quantity of these species in community can be considered, how the positive moment in reorganization microbial community of grounds.

Increase of Acetobacterium sp. (autochthonic microorganism) by the end of the composting period in 10 times can change acidity of environment locally, considering that this acetogenic culture capable to formation of acetic acid in process of an anaerobic metabolism [6]. Primary formation of acetic acid in comparison with other volatile fatty acids had been confirmed by a method of a gas chromatography (Table 2).

Hence, the transform of phosphorus, potassium and silicon in a water-soluble condition can occur both at the expense of stimulation of autochthonic microorganism's reproduction, which are capable to change acidity of environment locally and for the account of fermentative activity (in the leaching silica, for example, and other nutrients) of allochthonic microorganisms at the expense of biological preparations.

\section{Conclusion and Recommendation}

To regulate the biochemical process of ground transformation data is needed on what microbiological processes occur and which metabolizes of microorganisms that dominate the nutrients mobilization of this substrate. The knowledge about taxonomic composition of bacterial communities in a greenhouse ground is at an early stage. Nonetheless some important conclusions can be derived so far: 
1. The diatomite additives increased content of $\mathrm{P}, \mathrm{K}$, Si in 1.5-2 times.

2. The content of water-soluble elements forms in a ground with microorganisms after 56 days has increased: $\mathrm{P}$ and $\mathrm{K}$ - in 10 times, $\mathrm{Si}$ - in 3 times.

3. Both, autochthonic and allochthonic microorganisms are capable to increase the content of nutrients in a ground by fermentative activity and change acidity of environment locally.

The authors assume that such biological preparations will be effective in greenhouse ground.

\section{Reference}

[1] B.E. Jackson, R.D. Wright, M.M. Alley, Comparison of fertilizer nitrogen availability, nitrogen immobilization, substrate carbon dioxide efflux, and nutrient leaching in peat-lite, pine bark, and pine tree substrates, Hort. Science 44 (2009) 781-790.

[2] V.V. Matichenkov, D.V. Calvert, G.H. Snyder, Prospective of Si fertilization for reduction of $\mathrm{P}$ and $\mathrm{N}$ leaching from cultivated areas, in: Proc. Second Conference Si in Agriculture, Tsuruoka, Yamagata, Japan, 2002, p. 86.

[3] N.E. Samsonova, The role of silicon in the formation of phosphate regime of sod-podzolic soils, Agrochemistry 8 (2005) 11-18.

[4] M.P. Kolesnikov, Forms of silicon in plants, Success of Biological Chemistry 41 (2001) 301-332.
[5] T.V. Aristovskaya, Microorganism as a biogeocenosis component, Nauka, Moscow, Russia, 1984.

[6] J.W. Lengeler, G. Drews, H.G. Schlegel, Biology of the Prokaryotes, Thieme, Stuttgart, Georg Thieme Verlag, New York, 1999.

[7] V.V. Matichenkov, D. Calvert, G.H. Snyder, E.A. Bocharnikova, Effect of Si fertilization on growth and $\mathrm{P}$ nutrition of bahiagrass, Proc. Soil Crop Sci., Florida, 2001, pp. 30-36.

[8] W.L. Lindsay, Chemical Equilibrium in Soils, New York, 1979.

[9] H. Munk, The importance of silicate materials in the fertilization of crops, Agriculture Research, Special Issue 38, Conference, Trier, 1981.

[10] V.V. Matichenkov, D.V. Calvert, G.H. Snyder, Proc. 7th Inter. Conf. Wetland System for Water Pollution Control, Lake Bueno Vista, Florida, 2000.

[11] V.V. Matichenkov, V.M. Dyakov, E.A. Bocharnikova, The complex silicon-phosphate fertilizer, Russian patent, registration N97121543, Dec. 23, 1997.

[12] V.N. Kapranov, The efficiency of silicon-containing substance diatomite on soddy-podzolic soil, Prob. Agrochim. Ecol. 2 (2010) 10-15.

[13] G.A. Osipov, E.S. Turova, Studying species composition of microbial communities with the use of gas chromatography-mass spectrometry: microbial community of kaolin, FEMS Microb. Rev. 20 (1997) 437-446.

[14] N.V. Shekhovtsova, G.A. Osipov, N.V. Verkhovtseva, L.A. Pevzner, Analysis of lipid biomarkers in rocks of the Archean crystalline basement, Proceedings of SPIE 4939 (2003) 160-168. 